\title{
Evidence for Stem-Cell Niches in the Tracheal Epithelium
}

\author{
Duncan W. Borthwick, Mariam Shahbazian, Q. Todd Krantz, Julia R. Dorin, and Scott H. Randell
}

Medical Research Council Human Genetics Unit, Edinburgh, United Kingdom; U.S. Environmental Protection Agency, Research Triangle Park; and Cystic Fibrosis/Pulmonary Research and Treatment Center, The University of North Carolina, Chapel Hill, North Carolina

\begin{abstract}
It is generally important to elucidate airway epithelial cell lineages and to identify multipotent progenitors as targets for gene therapy. Stem $(S)$ cells are typically present in specialized compartments spatially proximal to their differentiated progeny, but an equivalent paradigm has not been demonstrated in the airway. We discovered a distinct population of cells displaying high levels of keratin expression in murine tracheal submucosal gland ducts, and tested the hypothesis that bromodeoxyuridine (BrdU) label-retaining cells (LRCs), thought to represent the $S$-cells, were present in this compartment. Mice received weekly epithelial damage by intratracheal detergent or $\mathrm{SO}_{2}$ inhalation for $4 \mathrm{wk}$ and received intraperitoneal injections of BrdU every $48 \mathrm{~h}$ during the injury and repair period. At 3 and $6 \mathrm{~d}$ after injury, BrdU-positive epithelial cells were noted along the entire tracheal length in both basal and lumenal cell positions. At later time points (20 and $95 \mathrm{~d}$ ) LRCs were localized to gland ducts in the upper trachea and to systematically arrayed foci in the lower trachea, typically near the cartilage-intercartilage junction. LRCs were not pulmonary neuroendocrine cells. Heterotopic tracheal grafts after surface epithelial removal demonstrated reconstitution of a surfacelike epithelium from gland remnants. These results suggest that airway epithelial $S$ cells are localized to specific niches.
\end{abstract}

Airway diseases such as asthma, chronic bronchitis, and cystic fibrosis are characterized by bronchial epithelial hyperplasia and metaplasia that likely contribute to the downward spiral of physiologic impairment. Elucidation of epithelial cell lineage is fundamental toward understanding mechanisms that alter epithelial phenotype. It is also important to identify cells with extensive progenitorial capacity as potential targets for gene therapy. Despite many studies directed at understanding the growth properties of specific subsets of cells constituting the pseudostratified airway epithelium, a definitive model establishing progenitor-progeny relationships in the normal steady state or in response to injury has not yet been established (1).

Stem (S)-cell theory divides epithelial cell types in renewing tissues into three major compartments according

(Received in original form April 18, 2000 and in revised form December 12, 2000)

EPA Disclaimer: This report has been reviewed by the National Health and Environmental Effects Research Laboratory, U.S. Environmental Protection Agency, and approved for publication. Approval does not signify that the contents necessarily reflect the views and policies of the agency, nor does mention of trade names and commercial products constitute endorsement or recommendation for use.

Address correspondence to: Scott H. Randell, Ph.D., UNC CF Center, CB 7248, Rm. 4011 Thurston-Bowles, Chapel Hill, NC 27599. E-mail: randell@ med.unc.edu

Abbreviations: $\beta$-galactosidase, $\beta$ gal; bromodeoxyuridine, BrdU; calcitonin gene-related peptide, CGRP; Griffonia simplicifolia isolectin $\mathrm{B}_{4}$, GSIB 4 ; immunoglobulin, Ig; label-retaining cell, LRC; pulmonary neuroendocrine cell, PNEC; parts per million, ppm; stem, S; transiently amplifying, TA; terminally differentiated, TD.

Am. J. Respir. Cell Mol. Biol. Vol. 24, pp. 662-670, 2001

Internet address: www.atsjournals.org to proliferation capacity and differentiation potential (recently reviewed in Refs. 2 and 3). S cells are pluripotent to generate all cell types in the tissue compartment and usually have adequate growth capacity for the life of the animal. In general, $\mathrm{S}$ cells turn over slowly and display minimal physiologic differentiation. As early descendents of $\mathrm{S}$ cells, transiently amplifying (TA) cells retain significant growth capacity while acquiring differentiated functions. TA cells eventually become incapable of proliferation and enter the terminally differentiated (TD) compartment. To conserve growth potential and to prevent genetic injury while vulnerable during mitosis, $\mathrm{S}$ cells are thought to cycle slowly and are recruited only as demanded by tissue turnover. Thus, much of the increase in cell number in the steady state occurs in the TA population. One consequence is that a pulse label of $\left[{ }^{3} \mathrm{H}\right]$ thymidine or bromodeoxyuridine (BrdU) will label mostly TA cells. Long-term $\left[{ }^{3} \mathrm{H}\right]$ thymidine or BrdU labeling will mark $\mathrm{S}$ cells that retain the label for an extended period due to slow turnover. Thus, an adequate labeling intensity and a suitable washout period of the TA and TD compartments will result in so-called label-retaining cells (LRCs) thought to represent the S-cell compartment.

In extensively studied tissues such as the epidermis, intestinal epithelium, and cornea, label-retaining $\mathrm{S}$ cells reside in specialized and generally well protected niches spatially proximal to their more differentiated TA and TD progeny. However, S-cell niches have not been demonstrated in the psuedostratified airway epithelium.

In studies aiming to isolate specific subpopulations of murine tracheal epithelial cells, we discovered a distinct population of cells displaying high levels of keratin gene and protein expression in submucosal gland ducts. Intriguingly, high keratin protein content in a subset of corneal epithelial cells (4) ultimately led to the discovery that LRCs of the cornea reside in the limbus (5). Further, expression of a specific keratin has been reported to be a marker for hair-follicle S cells (6). To determine whether the keratin-rich cells in the murine trachea were LRCs, we performed long-term BrdU labeling and washout studies of purposefully injured murine tracheas. Injury was required to stimulate cell division in the normally quiescent tracheal epithelium. Pulmonary neuroendocrine cells (PNECs) were localized to assess their role in S-cell patterning. Heterotopic tracheal grafts denuded of their surface epithelium were used to determine whether gland and gland duct remnants could reconstitute a surface-like epithelium.

\section{Materials and Methods \\ Transgenic Mice}

All animals were handled under Institutional Animal Care and Use Committee-approved protocols. The K5ßgal6000 transgenic 
mouse strain in which 6,000 base pairs (bp) of the basal cell-specific human keratin 5 promoter drives expression of the bacterial LacZ gene $(7,8)$ was a kind gift from Dr. Elaine Fuchs (University of Chicago, Chicago, IL). $\beta$-Galactosidase ( $\beta$ gal) activity in excised tissues was detected using X-gal substrate as previously described (9). Whole-mount images were obtained and tissues were processed for paraffin embedding. Sections were counterstained with nuclear fast red.

\section{Lectin and Keratin Staining}

Griffonia simplicifolia isolectin $\mathrm{B}_{4}\left(\mathrm{GSIB}_{4}\right)$ binding sites in mouse trachea were detected using biotinylated lectin as previously described (10). Polyclonal antibodies against the mouse homologues of human cytokeratin 14 and 18 were generated by immunizing rabbits with peptides CGKVVSTHEQVLRTKN$\mathrm{COOH}$ and CGRVVSETNDTRVLRH-COOH, respectively, conjugated to maleimide-activated ovalbumin or bovine serum albumin (Pierce, Rockford, IL). Antibodies were affinity-purified on peptide linked to maleimide-activated Sepharose (Pierce). Immunostaining was performed on formalin-fixed paraffin sections using Texas Red-labeled antirabbit antibody (Jackson Immunoresearch, West Grove, PA) and confocal microscopy.

\section{Induction of Epithelial Damage by Polidocanol or $\mathrm{SO}_{2}$}

Because the normal rodent tracheobronchial epithelium is mitotically quiescent, with $\sim 2 \%$ of the cells being labeled by a pulse of $\left[{ }^{3} \mathrm{H}\right]$ thymidine or $\operatorname{BrdU}(11,12)$, it is necessary to recruit $\mathrm{S}$ cells into the actively dividing pool to possibly visualize LRCs. Two methods of tracheal epithelial damage were used: intratracheal instillation of polidocanol (Sigma, St. Louis, MO), a detergent clinically used as a sclerosing agent and to facilitate gene transfer to airways (13); and $\mathrm{SO}_{2}$ inhalation, a well-studied model of pulmonary epithelial injury $(14,15)$.

Ten $\mu$ l of $2 \%$ polidocanol in phosphate-buffered saline (PBS) was directly instilled into the trachea just below the pharynx in anesthetized (intraperitoneal ketamine/xylazine mixture) CD1 mice (4- to 6-wk-old males; Charles River, Raleigh, NC). To assess the damage qualitatively, three animals were killed by barbiturate overdose at $10 \mathrm{~min}$ or 2 or $24 \mathrm{~h}$ after instillation and their tracheas were removed for conventional histology. Nine mice were exposed to an ambient environment of 500 parts per million (ppm) $\mathrm{SO}_{2}$ for $3 \mathrm{~h}$ in monitored chambers at the U.S. Environmental Protection Agency facility in Research Triangle Park, NC, and tracheal epithelial damage was assessed histologically at 2 or $24 \mathrm{~h}$.

\section{Repeated Damage and BrdU Labeling}

Male CD1 mice ( 6 wk old, $\sim 25 \mathrm{~g}$ ) received weekly tracheal damage by instillation of $10 \mu \mathrm{l}$ of $2 \%$ polidocanol or by $\mathrm{SO}_{2}$ inhalation (four escalating doses: 500 ppm for $3,3.5,4$, or $4.5 \mathrm{~h}$ ) as described earlier. In addition, the mice received intraperitoneal injections of BrdU ( $2 \mathrm{mg}$ ) every $48 \mathrm{~h}$ beginning $2 \mathrm{~h}$ after the first injury and extending until $24 \mathrm{~h}$ after the final injury. Groups of mice $(n=4-9)$ were killed at different time points (see Table 1$)$ and their tracheas were examined for BrdU incorporation by immunohistochemistry as described later. Controls included groups of mice receiving BrdU but without tracheal damage, and damaged mice receiving no BrdU.

\section{BrdU Immunohistochemistry}

BrdU incorporation was detected in sections of trachea and intestine using a staining procedure modified from previously reported methods (16). Fixation with Omnifix (FR Chemical, Mt. Vernon, NY) resulted in much stronger staining than with formalin and we also avoided antimouse immunoglobulin (Ig) G secondary antibodies to prevent high background. We used a fluorescein isothiocyanate (FITC)-labeled anti-BrdU monoclonal antibody (Caltag, Burlingame, CA) followed by rabbit anti-FITC IgG (Molecular Probes, Eugene, OR) which was detected with peroxidase-conjugated goat antirabbit IgG (Jackson Immunoresearch). Optimal antibody dilutions were determined empirically. A duplicate section was included on each slide in which an equal concentration of nonspecific FITC-labeled mouse IgG1 replaced the primary antibody. A positive control slide of a BrdU pulselabeled $(2 \mathrm{~h})$ mouse intestine was included in every staining session. This staining method was very sensitive, resulting in uniform, densely stained nuclei in crypt enterocytes after 2-h pulse labeling. As well as densely stained cells, we also observed fainter and heterogeneously labeled nuclei (small "dots" within the nuclei instead of uniformly brown nuclei) in the tracheas of animals chronically exposed to BrdU, possibly daughter cells in which BrdU was diluted.

\section{Measurement of BrdU Labeling}

Approximately 600 cells from three different regions (200/region) of every longitudinally sectioned trachea were examined for cell type and BrdU incorporation. The mouse trachea contains approximately 14 cartilage rings and, in the CD1 strain, tracheal glands are typically present only within the uppermost four rings (17). Region 1 began just above the most cephalad cartilage ring, with regions 2 and 3 beginning at rings 5 and 9 distal to the pharynx, respectively. A total of 100 consecutive cells beginning at each level on both sides of the trachea were scored. Staining was considered positive if the signal was nuclear and clearly above that detected as background on the adjacent negative control section, including faintly and heterogeneously stained nuclei. Cells were categorized as basal if they were small, cuboidal to squamoid in shape, and closely adherent to the basal lamina, and the nucleus was in the bottom third of the epithelial layer. All other cells were categorized as columnar. Several other studies have discriminated between specific cell types, but these investigations generally relied upon the higher resolution afforded by $\left[{ }^{3} \mathrm{H}\right]$ thymidine autoradiography on thin plastic or epoxy sections. Using Omnifix and paraffin embedding, and after acid and trypsin treatment needed for BrdU localization, we were confident discriminating only between basal and columnar cells. Areas of obvious artifact due to tissue processing were excluded. We noted densely stained BrdU-positive nuclei in the tracheas of mice chronically labeled with BrdU. Because these cells are of particular interest we categorized the specific location of each densely stained nucleus.

\section{Localization of PNECs}

PNECs are proposed to play important roles in pulmonary development and epithelial cell growth (18-22). We immunostained for calcitonin gene-related peptide (CGRP) to localize PNECs in the Day 95 experimental groups. Anti-CGRP (Sigma) was used

TABLE 1

Schedule for airway injury, BrdU injections, and tissue analysis

\begin{tabular}{lccccccccc}
\hline Day & 0 & 7 & 14 & 21 & 22 & & & & \\
Time Point & & & & & & $+3 \mathrm{~d}$ & $+6 \mathrm{~d}$ & $+21 \mathrm{~d}$ & $+95 \mathrm{~d}$ \\
\hline $\begin{array}{l}\text { Damage }^{\dagger} \\
\text { rrdU }^{\ddagger}\end{array}$ & $*$ & $*$ & $*$ & $*$ & & & & & \\
$n$
\end{tabular}

${ }^{\dagger}$ Injury was induced once per week as indicated (*) by inhalation of $500 \mathrm{ppm}$ $\mathrm{SO}_{2}$ or intratracheal instillation of $10 \mu \mathrm{l} 2 \%$ polidocanol solution.

$2 \mathrm{mg}$ of BrdU was administered intraperitoneally every $48 \mathrm{~h}$ beginning $24 \mathrm{~h}$ after the first injury until $24 \mathrm{~h}$ after the last injury. 


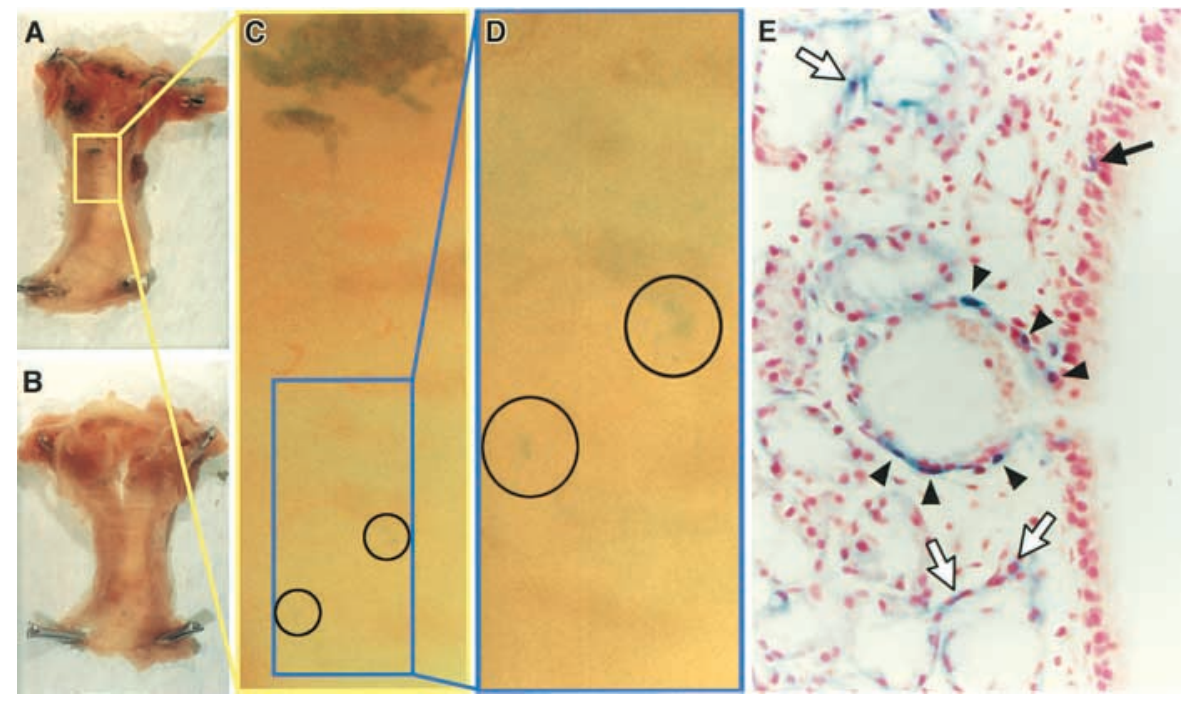

Figure 1. High levels of keratin 5 promoter activity in tracheal gland duct cells. Wholemount photographs of $\beta$ gal-stained tracheas from heterozygous K5 $\beta$ gal6000 mice $(A$, $C$, and $D$ ) or negative control littermates $(B)$ and a histologic section through a positive trachea at the level of a gland duct opening $(E)$. Squamous epithelial cells along the pharyngeal floor are positive (uppermost blue cells in $A$ ), as are cells in and around tracheal glands. Groups of faintly positive cells are visible in a descending posterior stripe (circled in $C$ and $D$ ). (E) Scattered surface basal cells (solid arrow), gland duct cells (arrowheads), and gland myoepithelial cells (open arrows) are stained. Original magnifications: $A$ and $B, \times 8 ; C$ and $D, \times 64 ; E, \times 400$.

as the primary antibody followed by biotinylated secondary antibody and streptavidin-peroxidase.

\section{Tracheal Grafts}

We studied heterotopic tracheal grafts to examine whether tracheal gland duct and/or acinar remnants could reconstitute a surface-like epithelium in denuded tracheas. Tracheas were removed from donor CD1 mice and the surface cells were removed by overnight incubation at $4^{\circ} \mathrm{C}$ in $0.1 \%$ Protease XIV (Sigma) in F-12 medium on a tilting platform. Histologic analysis demonstrated complete removal of the surface epithelium (illustrated in Figure 6). After surface denudation, Protease XIV action was terminated by addition of fetal bovine serum to $10 \%$ and the grafts were washed with three changes of F-12 medium. The pharyngeal opening and the trachea distal to ring 5 were closed with ligating clips. The upper, gland-containing tracheal portion was transplanted to the subcutaneous space of $\mathrm{Nu} / \mathrm{Nu}$ mice and allowed to grow for up to $42 \mathrm{~d}$ before removal and routine histologic analysis.

\section{Results and Discussion}

\section{Detection of a Keratin-Rich Compartment in the Murine Tracheal Epithelium}

In initial studies directed toward isolation of specific airway epithelial cell types, we localized $\beta$ gal activity in the trachea of transgenic mice in which $6,000 \mathrm{bp}$ of the basal cell-specific human keratin 5 promoter drives expression of the bacterial LacZ gene. These mice express $\beta$ gal in a pattern faithful to endogenous expression in several organs examined but with some notable exceptions (7), and high-level activity appears to correlate with growth potential in developing epidermis (8). Unexpectedly, $\beta$ gal activity was visible only in a circumferential band in the upper trachea, with a few small patches along a descending posterior stripe (Figures 1A, 1C, and 1D), a pattern most consistent with the localization of tracheal glands. No blue cells were visible in the lower trachea. Cross sections revealed scattered positive basal cells in the upper tracheal surface epithelium, prominently stained small groups of cells in the ducts of submucosal glands, and positive gland myoepithelial cells (Figure 1E). This was not due to an ab- sence of tracheal basal cells, which were clearly visible at all tracheal levels when stained with $\mathrm{GSIB}_{4}$ lectin (Figure $2 \mathrm{~A}$ ). As shown in Figures $2 \mathrm{~B}$ and $2 \mathrm{C}$, cellular $\beta$ gal activity correlated with high-level keratin protein expression as detected with antibodies against mouse keratins 14 and 18. Keratin 14 is usually coexpressed with keratin $5(23,24)$ and is present in surface basal cells and gland myoepithe-
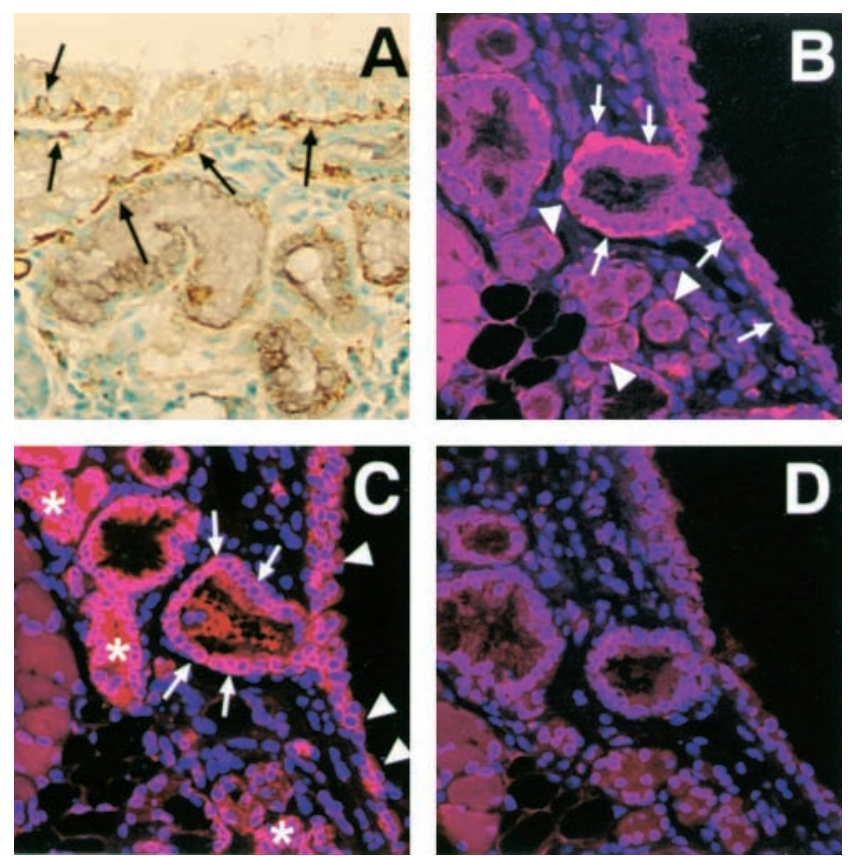

Figure 2. Keratin-rich cells in tracheal gland ducts. $\mathrm{GSIB}_{4}$ lectin $(A)$, keratin $14(B)$, keratin $18(C)$, and rabbit IgG control $(D)$ staining of mouse upper trachea. The surface epithelium has a continuous lining of basal cells that extend into the gland duct (arrows in A). Clusters of cells in the gland duct and surrounding surface epithelium as well as gland myoepithelial cells are keratin 14-positive (arrows and arrowheads in B, respectively). Gland duct cells, surface epithelial cells, and columnar acinar cells are keratin 18-positive (arrows, arrowheads, and asterisk in $C$, respectively). Original magnification in all panels: $\times 400$. 
lial cells. Keratin 18 is present in suprabasal, columnar surface cells and gland acinar cells. Interestingly, basal cells in gland ducts were positive for both keratins. These studies demonstrate the presence of a compartment of cells likely demonstrating very high keratin 5 promoter activity relative to other airway cell types. These cells abundantly contain both basal and nonbasal cell type-specific keratin proteins. This result is intriguing in that relatively high keratin content has been viewed as a biochemically primitive phenotype (4) and this observation led to formal demonstration that corneal epithelial S cells reside in the limbus (5).

\section{Damage Models to Enable Localization of LRCs in the Murine Tracheal Epithelium}

Prolonged metabolic labeling with $\left[{ }^{3} \mathrm{H}\right]$ thymidine or BrdU will mark epithelial S cells which, by virtue of their slow cycle time, will retain the label for an extended period. Rapidly renewing systems such as the epidermis (25-27) are amenable to localization of LRCs without additional recruitment of S cells, as was necessary for the cornea (5). Because the basal rate of mitosis in healthy airways is exceedingly low (11) it was necessary to injure the epithelium to cause cell proliferation. Two types of injury were used: intratracheal instillation of the detergent polidocanol, and $\mathrm{SO}_{2}$ inhalation. As shown in Figure 3, the direct instillation of $10 \mu \mathrm{l}$ of $2 \%$ polidocanol in PBS caused widespread removal of the epithelium. At first the superficial columnar layer was lost, and by $24 \mathrm{~h}$ patches of either epithelial remnants or denuded basal lamina were visible. Heterogeneity was possibly due to mechanical damage by the cannula during instillation and/or inhomogeneous physical dispersion of the detergent solution. At $2 \mathrm{~h}$ after inhalation of $500 \mathrm{ppm} \mathrm{SO}_{2}$, the superficial columnar epithelial cells uniformly displayed cytopathic changes indicative of degeneration. Gland acini appeared relatively empty and gland ducts were dilated with mucin. At $24 \mathrm{~h}$, the basal cell layer was largely retained. In both cases, eosinophilic material constituting a hyaline membrane was frequently observed. Within $3 \mathrm{~d}$ after both injuries, repair was well underway and a columnar layer was present but the percentage of the epithelial surface covered by cilia was still depressed. By $7 \mathrm{~d}$, a normal-appearing epi-
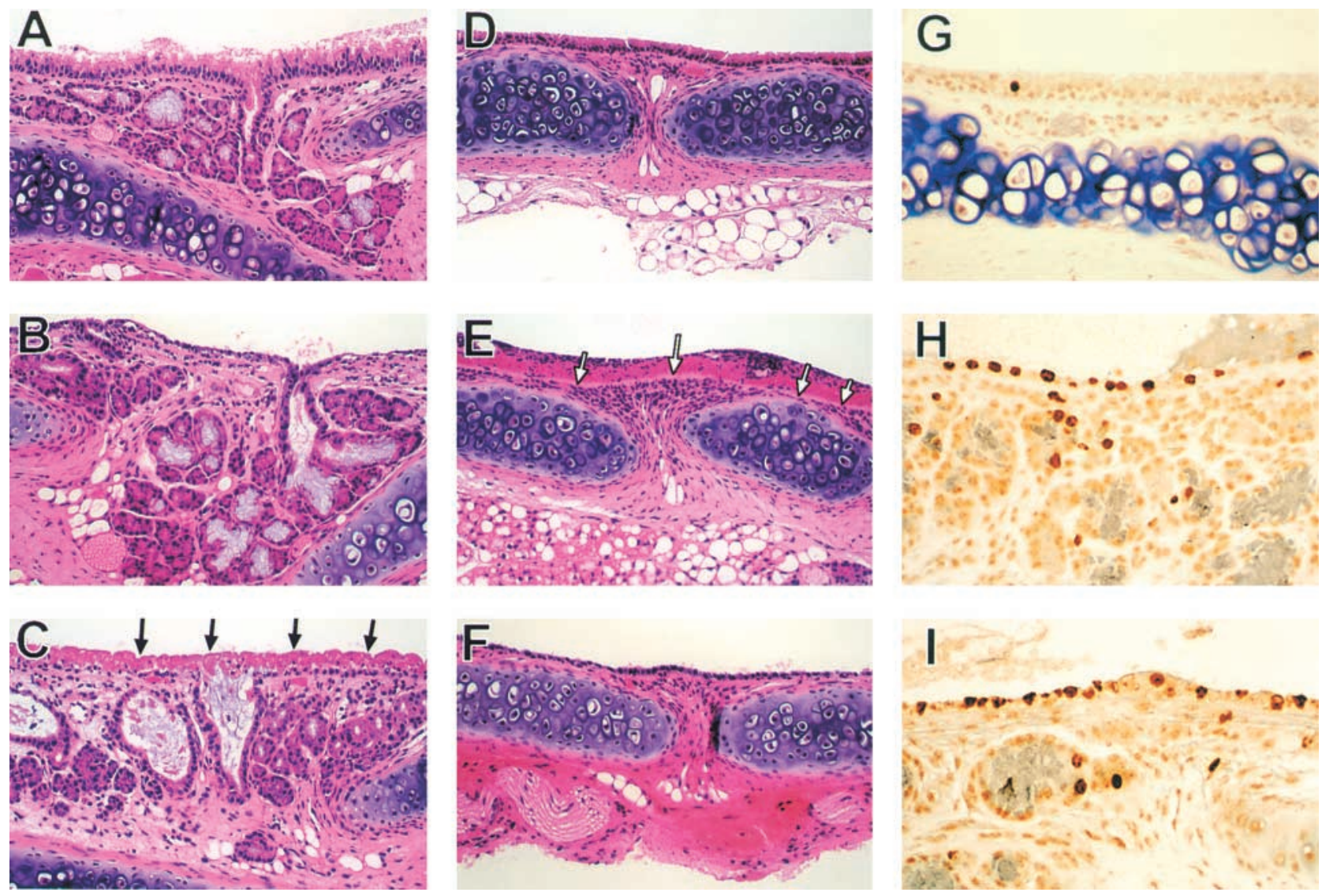

Figure 3. Characterization of tracheal epithelial injuries and the subacute proliferative response. Histologic sections of upper $(A-C$ and $G-I)$ or lower $(D-F)$ trachea from control $(A, D$, and $G)$, polidocanol-treated $(B, E$, and $H)$, or $\mathrm{SO}_{2}$-exposed $(C, F$, and $I)$ mice at $2(A-$ $C)$ or $24 \mathrm{~h}(D-I)$ after treatment. At $2 \mathrm{~h}$ after both injuries, cells closely adherent to the basal lamina persisted; eosinophilic material covered the epithelial surface $2 \mathrm{~h}$ after $\mathrm{SO}_{2}$ (arrows in $C$ ). By $24 \mathrm{~h}$ in polidocanol animals, there were patches of denuded basal lamina with an eosinophilic covering (arrows in $E$ ). However, $24 \mathrm{~h}$ after $\mathrm{SO}_{2}$, a uniform epithelial monolayer was present $(F)$. A 1-h pulse label of BrdU revealed a $1.3 \%$ labeling index in untreated controls $(G)$ but very high labeling of remaining epithelial cells $24 \mathrm{~h}$ after polidocanol $(H)$ or $\mathrm{SO}_{2}(I)$. A-F: hematoxylin and eosin stain, original magnification $\times 200 ; G-I$ : BrdU immunostaining, original magnification $\times 400$. 
thelium was re-established. Cell proliferation was assessed with a 1-h pulse label of BrdU $24 \mathrm{~h}$ after injury. Nuclear staining was negligible in isotype-matched antibody controls or in animals not receiving BrdU. An average tracheal BrdU labeling index of $1.3 \pm 0.3 \%$ (mean \pm standard error of the mean $[\mathrm{SEM}], \mathrm{n}=3$ ) was obtained from normal untreated animals. At $24 \mathrm{~h}$ after both injuries, the BrdU labeling index of viable surface epithelial cells was greater than $50 \%$.

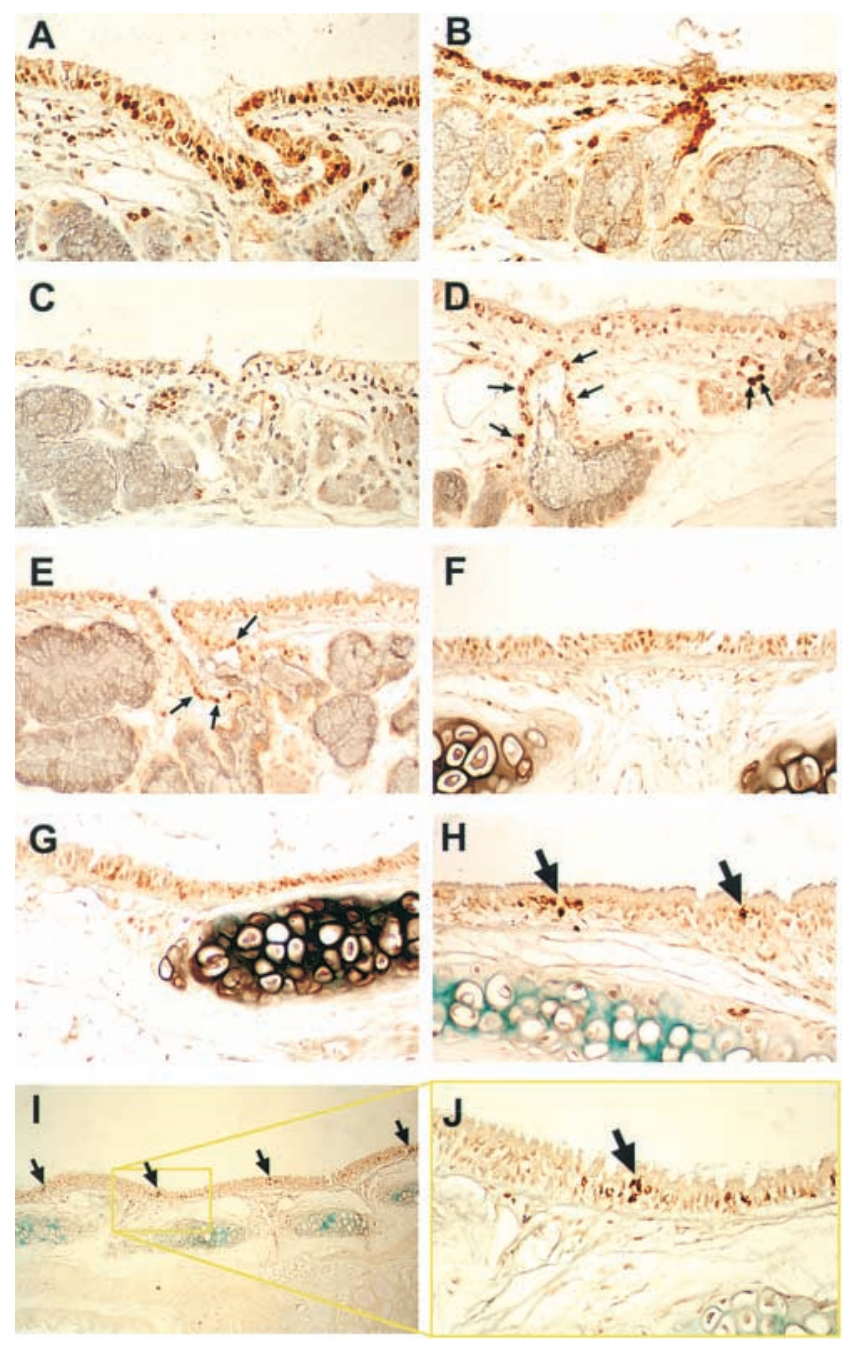

Figure 4. BrdU LRCs localize to upper tracheal gland ducts and to systematically arrayed foci in the lower trachea. Panels $A-D$ are sections of upper trachea from mice $3,6,22$, or $95 \mathrm{~d}$, respectively, after repeated $\mathrm{SO}_{2}$ injury and BrdU administration. Panel $E$ is from a polidocanol-treated mouse at $95 \mathrm{~d}$. Densely stained LRCs are clearly visible in gland ducts (arrows in $D$ and E). Panels $F-J$ are from the distal trachea. Panels $F$ and $G$ demonstrate a high labeling index in both basal and columnar cells $3 \mathrm{~d}$ after $\mathrm{SO}_{2}$ or polidocanol, respectively. Panel $H$ shows two foci of epithelial LRCs in the distal trachea $95 \mathrm{~d}$ after polidocanol treatment (arrows). Panels $I$ and $J$ are low- and high-power views, respectively, of distal trachea $95 \mathrm{~d}$ after $\mathrm{SO}_{2}$ treatment. Epithelial LRC clusters are systematically arrayed and tend to correspond to the location of the cartilage-intercartilage junction (arrows). All panels were immunostained for BrdU. Original magnifications: $A-H$ and $J, \times 400 ; I, \times 100$.

\section{Identification of LRCs in Repetitively Injured Tracheas Chronically Labeled with BrdU}

Mouse tracheas were injured with polidocanol or $\mathrm{SO}_{2}$ once per week for $4 \mathrm{wk}$ and the mice received $\mathrm{BrdU}$ injections every other day from the day of the first injury to $1 \mathrm{~d}$ after the last injury. There were no treatment-related mouse deaths in our studies, and groups of mice were killed at 3, 6, 21, and $95 \mathrm{~d}$ after the final injury. Trachea and duodenum were processed for BrdU immunostaining. Representative photomicrographs and morphometry results are shown in Figures 4 and 5, respectively. At the 3-d time point, BrdU-positive duodenal enterocytes were localized to the lower half and middle of the villus, whereas by $6 \mathrm{~d}$ only scattered positive cells were present at the villus tip, consistent with the known cell migration pattern in the crypt-villus unit (not shown). BrdU-positive enterocytes were no longer detectable at 21 and $95 \mathrm{~d}$. Positive nuclei were absent in animals that were injured but did not receive BrdU.
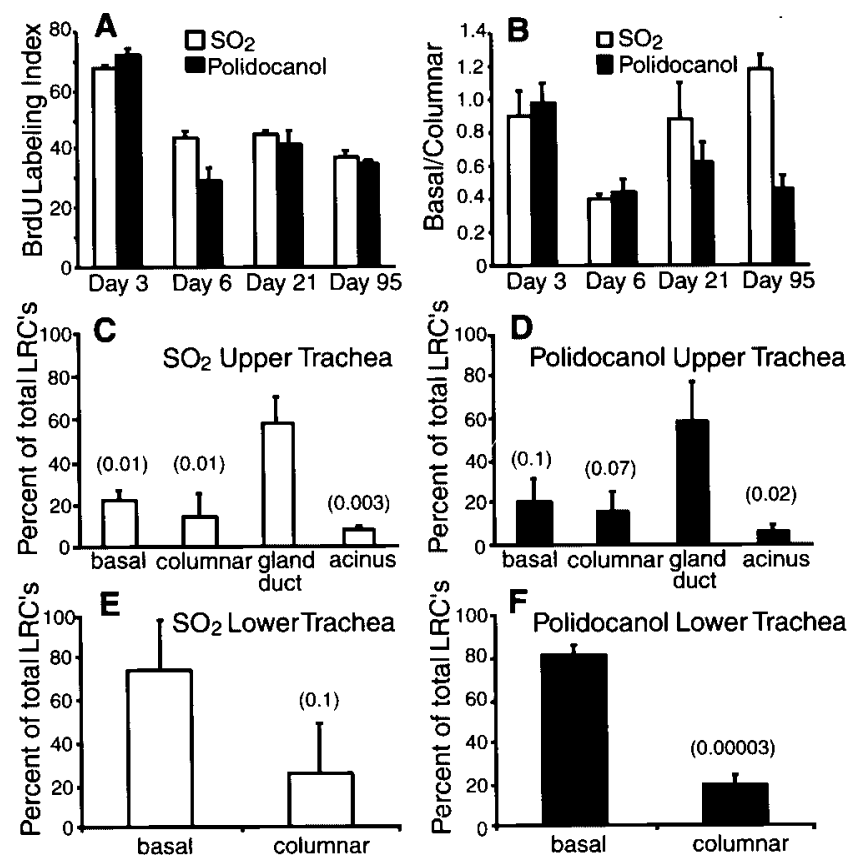

Figure 5. BrdU labeling index and locations of LRCs. $(A)$ The mean tracheal surface epithelial BrdU labeling index including both faintly and strongly labeled cells. There was a very significant overall time effect by analysis of variance (ANOVA) and $P<$ 0.05 for all comparisons with the Day 3 groups (two-tailed $t$ test). $(B)$ The ratio of BrdU-positive basal to columnar cells. There was a significant time effect by ANOVA. In the $\mathrm{SO}_{2}$ group, Day 6 is significantly different than all other time points, whereas in the polidocanol group Day 3 is significantly different than all other time points ( $P<0.05$, two-tailed $t$ test). In $A$ and $B$, values from the upper, middle, and lower trachea were not different and were averaged. $(C-F)$ The locations of strongly labeled cells in the upper and lower trachea $95 \mathrm{~d}$ after $\mathrm{SO}_{2}$ or polidocanol treatment expressed as percentages of the total strongly labeled cells. $P$ values for the comparison with gland duct in $C$ and $D$, and columnar versus basal in $E$ and $F$, are given in parentheses (twotailed $t$ test). Four or five animals were studied per time point. Values are means \pm SEM. 
Staining results in tracheas repetitively injured with polidocanol or $\mathrm{SO}_{2}$ and chronically labeled with $\mathrm{BrdU}$ were similar. At $3 \mathrm{~d}$ after the final injury ( 31 and $34 \mathrm{~d}$ after the first BrdU injections, respectively), the surface epithelial BrdU labeling index was approximately $65 \%$. BrdUpositive epithelial cells were noted in both luminal and basal positions along the surface of the entire trachea. In the tracheal gland system, duct, acinar, and myoepithelial cells were labeled. A heterogeneous pattern of nuclear BrdU staining was observed in both the surface epithelium and in glands. Many cells had focally positive "dots" within the nucleus and faint background staining of nuclear matrix, whereas other cells had more uniformly densely stained nuclei. Presumably, the fainter staining was due to dilution of the BrdU label, which occurred as cells proliferated in the absence of BrdU. Even at 3 and $6 \mathrm{~d}$, densely stained cells were preferentially localized to gland ducts and in scattered surface foci in both the upper and lower trachea. By 21 and $95 \mathrm{~d}$ after the last injury the overall BrdU staining was much weaker, although numerous faintly stained BrdU-positive cells were still visible. The labeling index, including faintly stained cells, still exceeded $30 \%$. Densely stained cells were preferentially localized to submucosal gland ducts in the upper trachea. Clusters of cells with strong BrdU staining were also systematically distributed along the surface epithelium in the glandless lower trachea and tended to correspond to the position of the cartilageintercartilage junction. The ratio of basal to columnar LRCs in the distal trachea was approximately 2 to 1 .

\section{LRCs Are Not PNECs}

PNECs are proposed to play important roles in lung development and as regulators of epithelial cell growth. The unique distribution of LRCs suggested a possible association with PNECs, and we used CGRP staining to assess the relationship. As illustrated in Figures $6 \mathrm{~A}$ and $6 \mathrm{~B}$, gland duct openings in the upper trachea were innervated with CGRP-positive fibers but PNECs were rare in this location. Because several LRCs were visible in each section from Day 95 animals containing gland ducts, it is clear that upper tracheal LRCs were not CGRP-positive PNECs. In the lower trachea, PNECs were frequently located near the cartilage-intercartilage junction where gland rudiments were occasionally found and where foci of LRCs were typically present. However, there were many more LRCs than PNECs. Thus, in the lower trachea, PNECs were systematically distributed along with LRCs, which may reflect their contribution to an airway trophic unit.

\section{Gland and Gland Duct Remnants Can Regenerate a Surface-like Epithelium}

Heterotopic tracheal grafts were used to test the hypothesis that gland and/or gland duct cells could contribute to surface epithelial regeneration. In this experiment, tracheas were harvested and the surface epithelium removed by exposure to protease. No remaining surface epithelial cells were seen in eight of eight protease-treated tracheas when viewed histologically (Figure 6C). Gland duct and acinar cells were present but were apparently "loosened" from the basal lamina by the protease. During the early stages after transplantation into $\mathrm{Nu} / \mathrm{Nu}$ mice the glands re- gressed, but by $28 \mathrm{~d}$ they had increased in size. Also at $28 \mathrm{~d}$, cystic spaces lined by a cuboidal epithelium containing ciliated cells appeared. Because of a lack of specific markers for gland ducts, it is impossible to determine whether this was a dilated gland duct structure or a new surface epithelium. However, the cells resembled the low cuboidal epithelium typically present in mouse bronchi. Although not conclusive, this experiment supports the idea that gland or gland duct cells can reconstitute a surface-like epithelium.

\section{Are Airway Epithelial Stem Cells Present in Distinct Morphologic Compartments?}

There has been a long-standing debate regarding the identity of airway epithelial S cells. Several studies suggest that basal cells are progenitors (28-32), but a strong proliferative response in secretory cells following injury (33), the late developmental appearance of basal cells (34-36), and studies with isolated cell populations (37) make a case for small-granule secretory cells or an undifferentiated columnar cell. There is evidence for great plasticity in growth and differentiation potential of airway epithelial cells (38) and our earlier studies showing that both basal and non-
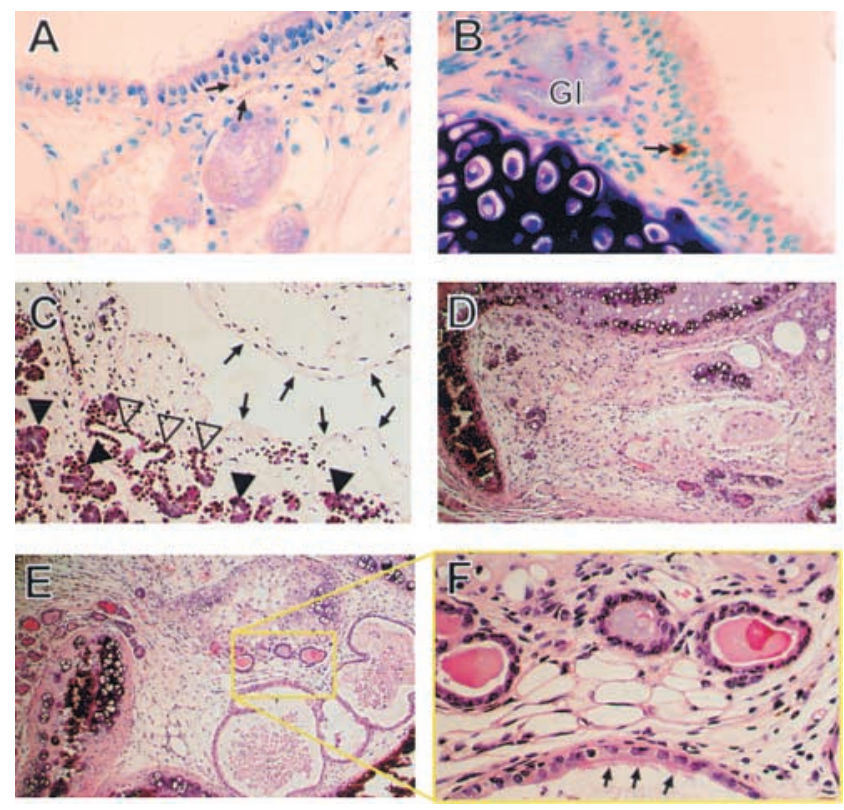

Figure 6. LRCs are not pulmonary neuroendocrine cells and gland remnants regenerate a surface-like epithelium. ( $A$ and $B$ ) Immunostaining for CGRP in upper and middle trachea, respectively, $95 \mathrm{~d}$ after $\mathrm{SO}_{2}$ exposure. Positive nerve fibers are visible in the lamina propria (arrows in $A$ ) but PNECs are not present in the epithelium that is predicted to have several LRCs. A solitary PNEC is visible in the surface epithelium (arrow in $B$ ) near a small gland rudiment (Gl) at the cartilage-intercartilage junction. Panel $C$ is from a protease-treated trachea before transplantation and shows complete removal of the surface epithelium (arrows) and "loosening" of gland duct (open arrowheads) and acinar (arrowheads) cells. Panel D shows small gland remnants $14 \mathrm{~d}$ after transplantation. Low- and high-power views of tracheal grafts $28 \mathrm{~d}$ after transplantation ( $E$ and $F$, respectively) show an increase in gland size and the presence of cystic spaces lined by a ciliated epithelium resembling the bronchial surface (arrows in $F$ ). Original magnification: $A, B$, and $F, \times 400 ; C, \times 200 ; D$ and $E, \times 100$. 
basal cells could regenerate a complete mucociliary epithelium in tracheal grafts support this notion $(16,39)$. However, detailed analysis of gland neogenesis in xenografts suggests that only a subset of human airway basal cells are pluripotent, at least to form glands (40). A critical factor in this debate is the specificity of the assay for "stemness." Within the context of a three-compartment model of cell lineages, DNA precursor LRCs have been considered synonymous with $\mathrm{S}$ cells in several renewing tissues $(5,27,41)$. To our knowledge, the present studies are the first attempt to localize LRCs in the respiratory tract. Because epithelial proliferation in the normal airway is too slow for sufficient S-cell labeling, we chose two different tolerable injuries. These treatments may not have been ideal in that both tended to selectively remove superficial cells. Loss of columnar cells and re-establishment of barrier function by basal cells appears to be a basic property of the pseudostratified epithelium (42). Selective removal of columnar cells may have obscured their potential contribution. Further studies, such as mechanical injury in the rat that cleanly denudes a portion of the epithelium, leaving both columnar and basal cells in the remaining portion (43), would be useful but this was not feasible in mice. Although $\left[{ }^{3} \mathrm{H}\right]$ thymidine labeling and autoradiography on thin plastic or epoxy sections would have enabled more accurate identification and quantification of labeled cells, we ruled out the use of isotope on the basis of expense, environmental impact, and the availability of BrdU as an alternative. Further, we had to decide on the route, dose, and frequency of BrdU administration. Preliminary experiments (S.H.R.'s unpublished results) with slow-release pellets that may have allowed for continuous labeling demonstrated unacceptable toxicity, and suitable implantable minipumps have only a 7-d duration. There was no adverse effect on body weight with the selected regimen of $2 \mathrm{mg} \mathrm{BrdU}$ every other day. Although this dose strongly labeled dividing cells within $1 \mathrm{~h}$, low BrdU plasma levels between injections probably resulted in labeling of only a subset of proliferating cells. Despite technical limitations due to injury type and incomplete cell labeling, we were nonetheless able to demonstrate clearly the preferential localization of LRCs to specific niches in the mouse trachea, namely, gland ducts in the upper trachea and systematically arrayed foci associated with the cartilage-intercartilage junction in the lower trachea. Perhaps these niches are analogous to "S cell clusters" present in the epidermis (44). Although these observations do not rule out a degree of progenitorial capacity among various tracheal-cell populations, they are most consistent with localization of airway epithelial S cells to distinct morphologic compartments. It is important to note that LRCs may be either slow-cycling S cells or residual TD cells. The latest time point that we studied was $95 \mathrm{~d}$, which we thought was a good compromise between the probable epithelial cell life span (which, to our knowledge, is not precisely known for the various cells of the mouse trachea) and loss of BrdU label. It is likely that high levels of proliferation occurred in locations between clusters of LRCs. Some of the LRCs we noted may have been residual TD cells, but minimal labeling of ciliated cells (the one airway epithelial cell type generally considered to have limited proliferation capacity) suggests that many of the LRCs were slowly cycling S cells. More studies are necessary to define tracheal cell life spans, to precisely map LRCs in three dimensions, and to illustrate patterns of cell proliferation and migration in relation to putative $S$ cell niches.

\section{A “Zonal Model” for Airway Epithelial Stem Cells}

One may envision the respiratory tract as comprised of distinct "zones" with different cell lineage systems. Epithelial cell composition and zone boundaries depend on both the species and the individual animal history. In normal mice, a renewing cell system encompassing a glandcontaining, pseudostratified epithelium with Clara cells and few goblet cells is present in the upper trachea. In rats, a similar system, but with more goblet cells and no Clara cells, is present in the entire trachea; whereas in humans this zone penetrates many bronchial generations. Distally, the airway epithelium becomes glandless, cuboidal, and dominated by a Clara cell-based lineage system (45) before transitioning to a type II cell-based system (46) in the alveoli. After injury or infection, cell composition and/or positional boundaries may change. For example, glands may form more distally, accompanied by goblet-cell metaplasia in small airways or bronchiolarized metaplasia of the proximal alveolar region. Our results showing localization of LRCs to upper tracheal gland ducts and to distinct foci in the glandless distal trachea illustrate the presence of related, but likely different, lineage systems in these different airway zones.

\section{"Trophic Units" in the Airway Epithelium}

Distal tracheal foci of LRCs tended to correspond with the position of the cartilage-intercartilage junction where blood vessels and nerves typically penetrate toward the epithelial surface $(47,48)$, where gland rudiments were occasionally observed (this study), and where single PNECs were frequently present in the surface epithelium (this study). Reciprocal epithelial-mesenchymal interactions involving specific gene regulatory systems govern morphogenesis in many organ systems (for recent review, see Ref. 49). Most of the available data in lung focuses on developmental branching morphogenesis (50), but recent studies implicate the lymphoid enhancer factor 1 pathway as a regulator of airway gland neogenesis (51). Mesenchymal, neural, and epithelial elements within a defined structural framework likely constitute a so-called "trophic unit" of the mammalian airway. There may also be a systematic relationship between such units and respiratory tract field cancerization (52). It is interesting that a niche of LRCs was present in tracheal submucosal gland ducts. We speculate that cells in this location are strategically poised to serve as a reserve in the event of cataclysmic injury - such as gastric acid aspiration or smoke inhalation-and as a source of cells to form, expand, and/or maintain submucosal glands. Although the developmental derivation of airway glands from the surface epithelium indicates a functional relationship, it is also possible that their cell regeneration systems in the adult are separate. In the latter case, the persistence of LRCs within gland ducts may have been due to a lesser degree of injury and slower cell turnover in the relatively protected gland compartment. Lineage-mapping studies 
may help to resolve this issue. The relationship of LRCs in gland ducts to oncocytes (53) or cystic fibrosis transmembrane conductance regulator-rich "flasklike cells" (54) remains to be determined.

\section{Conclusions}

This report suggests the existence of S-cell niches in the pseudostratified airway epithelium. Potential S-cell targets for gene therapy likely reside within gland ducts and in foci systematically arrayed along the surface of glandless airways. Further studies are needed to discover unique markers of airway epithelial S-cells, to better understand the niche microenvironment, and to isolate and test putative airway epithelial S cells.

Acknowledgments: The authors gratefully acknowledge expert technical support by Tracy Bartollotta and Kimberlie Burns of the UNC CF Center Histology Core, and thank Dr. Euan Slorach for critical reading of the manuscript. The authors thank Dr. Elaine Fuchs for providing the K5Bgal6000 transgenic mice. This work was supported by NIH grant HL58345 to one author (S.H.R.) and by support to one author (J.R.D.) from the MRC.

\section{References}

1. Mason, R. J., M. C. Williams, H. L. Moses, S. Mohla, and M. A. Berberich. 1997. Stem cells in lung development, disease, and therapy. Am. J. Respir. Cell Mol. Biol. 16:355-363.

2. Watt, F. M., and B. L. Hogan. 2000. Out of eden: stem cells and their niches. Science 287:1427-1430.

3. Slack, J. M. 2000. Stem cells in epithelial tissues. Science 287:1431-1433.

4. Schermer, A., S. Galvin, and T. T. Sun. 1986. Differentiation-related expression of a major $64 \mathrm{~K}$ corneal keratin in vivo and in culture suggests limbal location of corneal epithelial stem cells. J. Cell Biol. 103:49-62.

5. Cotsarelis, G., S. Z. Cheng, G. Dong, T. T. Sun, and R. M. Lavker. 1989. Existence of slow-cycling limbal epithelial basal cells that can be preferentially stimulated to proliferate: implications on epithelial stem cells. Cell 57:201-209.

6. Lyle, S., M. Christofidou-Solomidou, Y. Liu, D. E. Elder, S. Albelda, and G. Cotsarelis. 1998. The C8/144B monoclonal antibody recognizes cytokeratin 15 and defines the location of human hair follicle stem cells. J. Cell Sci. 111:3179-3188.

7. Byrne, C., and E. Fuchs. 1993. Probing keratinocyte and differentiation specificity of the human K5 promoter in vitro and in transgenic mice. Mol. Cell. Biol. 13:3176-3190.

8. Byrne, C., M. Tainsky, and E. Fuchs. 1994. Programming gene expression in developing epidermis. Development 120:2369-2383.

9. Cepko, C., E. F. Ryder, C. P. Austin, C. Walsh, and D. M. Fekete. 1995. Lineage analysis using retrovirus vectors. Methods Enzymol. 254:387-419.

10. Shimizu, T., P. Nettesheim, J. F. Mahler, and S. H. Randell. 1991. Cell typespecific lectin staining of the tracheobronchial epithelium of the rat: quantitative studies with Griffonia simplicifolia I isolectin B4. J. Histochem. Cytochem. 39:7-14.

11. Evans, M. J., S. S. 1989. Lung Cell Kinetics. In Lung Cell Biology. D. Massar, editor. Marcel Dekker, New York. 1-36.

12. Taya, A., A. Morgan, S. T. Baker, J. A. Humphreys, M. Bisson, and C. G. Collier. 1994. Changes in the rat lung after exposure to radon and its progeny: effects on incorporation of bromodeoxyuridine in epithelial cells and on the incidence of nuclear aberrations in alveolar macrophages. Radiat. Res. 139:170-177.

13. Parsons, D. W., B. R. Grubb, L. G. Johnson, and R. C. Boucher. 1998. Enhanced in vivo airway gene transfer via transient modification of host barrier properties with a surface-active agent. Hum. Gene Ther. 9:2661-2672.

14. Kavet, R. I., and J. D. Brain. 1974. Reaction of the lung to air pollutant exposure. Life Sci. 15:849-861.

15. Lamb, D., and L. Reid. 1968. Mitotic rates, goblet cell increase and histochemical changes in mucus in rat bronchial epithelium during exposure to sulphur dioxide. J. Pathol. Bacteriol. 96:97-111.

16. Liu, J. Y., P. Nettesheim, and S. H. Randell. 1994. Growth and differentiation of tracheal epithelial progenitor cells. Am. J. Physiol. 266:L296-L307.

17. Borthwick, D. W., J. D. West, M. A. Keighren, J. H. Flockhart, B. A. Innes, and J. R. Dorin. 1999. Murine submucosal glands are clonally derived and show a cystic fibrosis gene-dependent distribution pattern. Am. J. Respir. Cell Mol. Biol. 20:1181-1189.

18. Peake, J. L., S. D. Reynolds, B. R. Stripp, K. E. Stephens, and K. E. Pinkerton. 2000. Alteration of pulmonary neuroendocrine cells during epithelial repair of naphthalene-induced airway injury. Am. J. Pathol. 156:279-286.
19. Reynolds, S. D., A. Giangreco, J. H. Power, and B. R. Stripp. 2000. Neuroepithelial bodies of pulmonary airways serve as a reservoir of progenitor cells capable of epithelial regeneration. Am. J. Pathol. 156:269-278.

20. Emanuel, R. L., J. S. Torday, Q. Mu, N. Asokananthan, K. A. Sikorski, and M. E. Sunday. 1999. Bombesin-like peptides and receptors in normal fetal baboon lung: roles in lung growth and maturation. Am. J. Physiol. 277: L1003-L1017.

21. Hoyt, R. F. Jr., N. A. McNelly, E. M. McDowell, and S. P. Sorokin. 1991. Neuroepithelial bodies stimulate proliferation of airway epithelium in fetal hamster lung. Am. J. Physiol. 260:L234-L240.

22. Hoyt, R. F., Jr., S. P. Sorokin, E. M. McDowell, and N. A. McNelly. 1993. Neuroepithelial bodies and growth of the airway epithelium in developing hamster lung. Anat. Rec. 236:15-22; discussion 22-14.

23. Fuchs, E., and C. Byrne. 1994. The epidermis: rising to the surface. Curr. Opin. Genet. Dev. 4:725-736.

24. Fuchs, E. 1995. Keratins and the skin. Annu. Rev. Cell Dev. Biol. 11:123-153.

25. Lavker, R. M., and T. T. Sun. 1983. Epidermal stem cells. J. Invest. Dermatol. $81: 121 \mathrm{~s}-127 \mathrm{~s}$

26. Bickenbach, J. R., and I. C. Mackenzie. 1984. Identification and localization of label-retaining cells in hamster epithelia. J. Invest. Dermatol. 82:618-622.

27. Mackenzie, I. C., and J. R. Bickenbach. 1985. Label-retaining keratinocytes and Langerhans cells in mouse epithelia. Cell Tissue Res. 242:551-556.

28. Donnelly, G. M., D. G. Haack, and C. S. Heird. 1982. Tracheal epithelium: cell kinetics and differentiation in normal rat tissue. Cell Tissue Kinet. 15:119-130.

29. Breuer, R., G. Zajicek, T. G. Christensen, E. C. Lucey, and G. L. Snider. 1990. Cell kinetics of normal adult hamster bronchial epithelium in the steady state. Am. J. Respir. Cell Mol. Biol. 2:51-58.

30. Ford, J. R., and M. Terzaghi-Howe. 1992. Characteristics of magnetically separated rat tracheal epithelial cell populations. Am. J. Physiol. 263:L568L574.

31. Ford, J. R., and M. Terzaghi-Howe. 1992. Basal cells are the progenitors of primary tracheal epithelial cell cultures. Exp. Cell Res. 198:69-77.

32. Boers, J. E., A. W. Ambergen, and F. B. Thunnissen. 1998. Number and proliferation of basal and parabasal cells in normal human airway epithelium. Am. J. Respir. Crit. Care Med. 157:2000-2006.

33. McDowell, E. M., J. W. Combs, and C. Newkirk. 1983. Changes in secretory cells of hamster tracheal epithelium in response to acute sublethal injury: a quantitative study. Exp. Lung Res. 4:227-243.

34. Plopper, C. G., J. L. Alley, and A. J. Weir. 1986. Differentiation of tracheal epithelium during fetal lung maturation in the rhesus monkey Macaca mulatta. Am. J. Anat. 175:59-71.

35. Broers, J. L., L. de Leij, M. K. Rot, A. ter Haar, E. B. Lane, I. M. Leigh, S. S. Wagenaar, G. P. Vooijs, and F. C. Ramaekers. 1989. Expression of intermediate filament proteins in fetal and adult human lung tissues. Differentiation 40:119-128.

36. McDowell, E. M., C. Newkirk, and B. Coleman. 1985. Development of hamster tracheal epithelium: II. Cell proliferation in the fetus. Anat. Rec. 213:448-456.

37. Johnson, N. F., and A. F. Hubbs. 1990. Epithelial progenitor cells in the rat trachea. Am. J. Respir. Cell Mol. Biol. 3:579-585.

38. Basbaum, C., and B. Jany. 1990. Plasticity in the airway epithelium. Am. J. Physiol. 259:L38-L46.

39. Randell, S. H., C. E. Comment, F. C. Ramaekers, and P. Nettesheim. 1991. Properties of rat tracheal epithelial cells separated based on expression of cell surface alpha-galactosyl end groups. Am. J. Respir. Cell Mol. Biol. 4: 544-554.

40. Engelhardt, J. F., H. Schlossberg, J. R. Yankaskas, and L. Dudus. 1995. Progenitor cells of the adult human airway involved in submucosal gland development. Development 121:2031-2046.

41. Cotsarelis, G., T. T. Sun, and R. M. Lavker. 1990. Label-retaining cells reside in the bulge area of pilosebaceous unit: implications for follicular stem cells, hair cycle, and skin carcinogenesis. Cell 61:1329-1337.

42. Erjefalt, J. S., F. Sundler, and C. G. Persson. 1997. Epithelial barrier formation by airway basal cells. Thorax 52:213-217.

43. Shimizu, T., M. Nishihara, S. Kawaguchi, and Y. Sakakura. 1994. Expression of phenotypic markers during regeneration of rat tracheal epithelium following mechanical injury. Am. J. Respir. Cell Mol. Biol. 11:85-94.

44. Jensen, U. B., S. Lowell, and F. M. Watt. 1999. The spatial relationship between stem cells and their progeny in the basal layer of human epidermis: a new view based on whole-mount labelling and lineage analysis. Development 126:2409-2418.

45. Evans, M. J., L. V. Johnson, R. J. Stephens, and G. Freeman. 1976. Renewal of the terminal bronchiolar epithelium in the rat following exposure to $\mathrm{NO} 2$ or O3. Lab. Invest. 35:246-257.

46. Evans, M. J., L. J. Cabral, R. J. Stephens, and G. Freeman. 1975. Transformation of alveolar type 2 cells to type 1 cells following exposure to NO2. Exp. Mol. Pathol. 22:142-150.

47. Baker, D. G., D. M. McDonald, C. B. Basbaum, and R. A. Mitchell. 1986. The architecture of nerves and ganglia of the ferret trachea as revealed by acetylcholinesterase histochemistry. J. Comp. Neurol. 246:513-526.

48. McDonald, D. M. 1988. Neurogenic inflammation in the rat trachea: I Changes in venules, leucocytes and epithelial cells. J. Neurocytol. 17:583-603. 
49. Hogan, B. L. 1999. Morphogenesis. Cell 96:225-233.

50. Hogan, B. L., and J. M. Yingling. 1998. Epithelial/mesenchymal interactions and branching morphogenesis of the lung. Curr. Opin. Genet. Dev. 8:481-486.

51. Duan, D., Y. Yue, W. Zhou, B. Labed, T. C. Ritchie, R. Grosschedl, and J.F. Engelhardt. 1999. Submucosal gland development in the airway is controlled by lymphoid enhancer binding factor 1 (LEF1). Development 126:4441-4453.

52. Franklin, W. A., A. F. Gazdar, J. Haney, Wistuba, II, F. G. La Rosa, T.
Kennedy, D. M. Ritchey, and Y. E. Miller. 1997. Widely dispersed p53 mutation in respiratory epithelium. A novel mechanism for field carcinogenesis. $J$. Clin. Invest. 100:2133-2137. [published erratum J. Clin. Invest. 1997 100:2639] 53. Matsuba, K., T. Takizawa, and W. M. Thurlbeck. 1972. Oncocytes in human bronchial mucous glands. Thorax 27:181-184.

54. Engelhardt, J. F., M. Zepeda, J. A. Cohn, J. R. Yankaskas, and J. M. Wilson. 1994. Expression of the cystic fibrosis gene in adult human lung. $J$. Clin. Invest. 93:737-749. 